\title{
Modo, continente y contenido: \\ en pos de las bisagras conceptuales (modernidad, espacio urbano y cultura)'
}

\author{
Arturo E. García Niño
}

\section{Pre/texto}

U no de los primigenios retos que nos saltan al paso al penetrar el terreno del trabajo historiográfico es el de las opciones, las disyuntivas, las encrucijadas. Ello empieza cuando en el cruce de caminos temáticos elegimos: momentos, actores sociales, espacios, movimientos, actividades productivas, clases sociales... lo que se ha convertido ahora en lo que es para nosotros. Exploramos entonces en la selva conceptual y estilística: cuáles podrán ser las herramientas teóricas para el análisis (en caso de que lo haya) y cómo vamos a contarlo

1. El presente trabajo es un atisbo, un inicial peldaño en la construcción del marco teórico para la investigación titulada Hay puertos que sí hacen nuido (cultura y vida social en el puerto de Veracruz durante los años veinte), tesis con la que el autor aspira a obtener el Doctorado en Historia y Estudios Regionales. Esta primera delimitación teóricoconceptual hace énfasis en los conceptos de modernidad, espacio urbano y cultura, revisando algunas de las propuestas fundamentales en torno a éstos. Asimismo, cómo el concepto "habermasiano" de esfera pública puede servir de "bisagra" entre los tres mencionados. Con tales precedentes a manera de guía para el forastero, el autor pretende analizar el tema central de investigación y precisar qué era lo que hacía por aquellos años al puerto de Veracruz un crisol citadino convocante e irradiante, quiénes eran y cómo se relacionaban y cómo vivían y qué hacían y en dónde y de qué manera los habitantes de este continente acotado del actuar humano que era la ciudad señalada. La intención de publicarlo tiene dos finalidades: una muy personal e interesada, que es someterlo a discusión con los colegas lectores y obtener de ahí aportes; la otra, también muy personal pero desinteresada, que es dejarles a los estudiantes de licenciatura y futuros colegas una muestra de bulto acerca del cómo se puede ir delimitando teóricamente para construir el marco teórico de un trabajo de investigación. Los dos objetivos, uno convenenciero y existencial y otro servicial y pedagógico, esperan ser cumplidos para el bienestar del susodicho autor.

2. Universidad Veracruzana. 
(lo referente a la narrativa). Caminar en el filo de la navaja anterior genera una contante tensión que, en ocasiones, desfase los trabajos y da como resultado interpretaciones sociologizadas de la historia o descripciones asépticas e informativas de la misma. Y aunque cada una de tales corrientes (que las hay, existen) no deja de aportar a la historiografía, la ausencia del diálogo conceptual/narrativo echa a un lado posibilidades y filones informativos y teóricos que, vistos desde otra óptica, arrojarían mayor riqueza en el terreno del conocimiento sobre lo acontecido en el pasado. Este es, sin duda, el primer foco rojo que se debe prender y buscar desde ahí el punto de encuentro necesario entre la teoría social como aporte central al trajinar de la historia. Pero también de ese encuentro puede la teoría social obtener riqueza de la historia. Ambas saldrán en mejores condiciones del diálogo, en lugar de las funestas y nada gratas consecuencias que se obtienen por el divorcio entre las dos (Kofler, 1974).

La preocupación citada líneas atrás se encuentra presente en las reflexiones particulares de quien estas cuartillas perpetra: cómo articular el diálogo entre teoría y el bien/buen contar las cosas, los hombres y los acontecimientos. Por ahí, en este andar, optamos por apropiarnos de un principio que, quizás, resulte un "subterfugio metodológico" cómodo pero en el cual creemos: para comprender algo hay que ubicarlo en situación dialogal y que comprender implica, siempre, comprender de otro modo, de manera diversificada, lo que le otorga a cada acto o intentona de comprensión (en nuestro caso de comprensión teórica específica) su validez y razón de ser en el terreno que se dé (Gadamer, 1992). En tal sentido, creemos, todo trabajo historiográfico deberá, por lo menos, intentar propiciar el diálogo pasado-presente. En otro orden pero en la misma lógica, se encuentra lo concerniente a lo que pudiéramos denominar el "recorte teórico conceptual" al interior del trabajo, lo que, a fin de cuentas, terminarán siendo las entrañas del resultado final, Para tal cuestión, y retomando como paraguas al irrenunciable Borges, asumimos precisamente la necesidad y procedencia del mencionado recorte como elemento substancial de la labor científica, oponiéndonos, en total acuerdo con nuestro autor, a la elaboración de un mapa del tamaño del país a representar, mismo que no sirve para nada de lo que supuestamente es su objetivo; nos deslindamos de este mal entendido "rigor en la ciencia" (1989). Asimismo, no es posible perder de vista que partiendo de lo que Ricoeur llama la "mediación primaria", la del sí mismo (1996). Como seres en situación que somos abordaremos, desde nuestra conformación e historia de vida particulares, el tema.

La pertinencia del diálogo interdisciplinario, tanto en sentido diacrónico como sincrónico, es una apuesta que, hasta ahora, viene mostrando su bondadosa consecuencia, Bajo ella nos arropamos en el intento por indagar en torno a la cultura y la vida social en el puerto de Veracruz durante los años veinte. Haremos, entonces, una pesquisa que nos permita articular los conceptos de 
Modernidad, Espacio Urbano y Cultura, en un diálogo interior, para luego ampliarlo con el concepto de Esfera Pública (Habermas, 1998). De tal intento pensamos obtener los primeros apuntes de lo que vendría a ser un marco teórico en un futuro posible (por ahora será una delimitación teórica primaria). Pero antes de enlazarnos con el campo de batalla expositivo y analítico de los conceptos vale la pena esbozar, sintéticamente, las razones bajo las cuales se determinaron tema, tiempo y espacio. ${ }^{3}$

Independientemente de lo que consideramos las tres primeras modernidades que, en mayor o menor medida inciden en Veracruz, puerto (la Conquista, la Independencia y la Reforma), es la cuarta (la Revolución de 1910) el motivo de incidencia mayor y más cercano para nuestro objeto. Inacabada por entonces y quizás por ello mismo (Habermas, 1988), permite que el puerto devenga privilegiado lugar donde se cruzan y co/inciden los conceptos que dan pie a estas líneas. Vayan aquí algunas preguntas y afirmaciones en abono: cuáles son las afluentes que le dan sentido al ser porteño, de dónde provienen las incidencias que resultan coincidencias, de qué manera son usados los productos de la cultura política emanada de variopintos rumbos, cómo se reorganizan y resemantizan éstos, en qué espacios detectar los entrecruzamientos de la circulación cultural, qué amarra las expresiones de la cultura de élite con las culturas populares y de la política con el ejercicio de la vida cotidiana, cómo se articulan las tomas de sentido del mundo con la actuación sobre éste, cómo y desde qué y dónde se deslindan los espacios de lo público y lo privado, cuál es el papel de la técnica y la tecnología en la creación de los imaginarios en esa época, qué peso específico tienen lo lúdico (la música, el baile, la literatura, el cine, la fotografía...) y las expresiones religiosas, cómo se acrisolan las vertientes para dar origen a lo que andamos indagando (Martín-Barbero, 1987; García Canclini, 1982, 1990, 1991; Barthes, 1991; De Certeau, 1996; Benjamin, 1982, 1982a, 1989; Borges, 1990; Bajtin, 1974; Lafaye, 1977; Prost y Vincent, 1987; Nettel y Arroyo, 1997; García Niño, 1992.

Las preguntas anteriores se imbrican con el porqué del tiempo y el lugar: porque el puerto es por entonces una suerte de laboratorio en el cual convergen algunos de los proyectos caudillistas, porque el proyecto de nación revolucionario inicia su definición, porque la vecindad con el Golfo de México y el Caribe lo ubican en privilegiada posición como cruce de caminos, porque el anarcosindicalismo tiene aquí sus posibilidades más amplias de socialización y acción al empatarse con el liberalismo producto del XIX, porque la

3. Un texto importante a mi entender, aunque poco apreciado, que lleva a cabo de manera brillante el diálogo pasado-presente es el de Jorge Aguilar Mora (1990); un texto que aplica el concepto de esfera públicá a procesos sociales del siglo XIX es el de Celia del Palacio Montiel (1997); trabajo nodal sobre la teoría social aplicada al rastreo histórico de ella misma para de ahí analizar las dinámicas contemporáneas es el de Jesús MartínBarbero (1987). 
industria naciente ya desplaza al artesano y origina al obrero como ser social "nuevo y moderno", porque era el centro urbano más importante del estado, porque el concepto e idea de ciudad es aquí donde arraiga y se define primero que en ningún otro lugar de la entidad... Por todo ello el tema, el tiempo y el espacio. Por todo ello la búsqueda de un obligado engrane entre los conceptos ya citados. Por todo ello es tiempo de convocarlos en nuestra ayuda, para vislumbrar su autonomía y conjunción, lo que nos permitirá, pensamos,

localizar en el pasado las causas de lo que sucedió después.... Y delinear el proceso por el que esas causas se encaminaron lentamente hacia la producción de sus efectos. (Eco, 1985: 81)

\section{El modo}

Partamos de los acuerdos, de lo sabido por afirmado, argumentado y, en muchos de los casos, demostrado: la mayor parte de los autores dignos de tomarse en cuenta coinciden en algunos puntos centrales acerca de la modernidad. De Habermas a Lyotard pasando por Jameson, Berman y Baudrillard, por ejemplo, hay certezas y coincidencias en que ésta arranca con el proyecto de la ilustración, de que antes de ser una época es un modo de sentir, concebir y actuar, que es una experiencia, de que el siglo XVIII es su escenario de aparición, pero que cobra suma importancia en la configuración del XIX y el $\mathrm{XX}$, que corre de manera pareja con el desarrollo del capitalismo, que bajo sus particularidades asistimos a la conformación del Estado Nación, que... Así encontramos en Max Weber una equivalencia importante entre lo que sería la historia moderna (entendida como la de occidente) e historia del capitalismo y su modo, lo que le da razón y esencia: la ética protestante (1994). Para Habermas el proyecto moderno es

el mismo de la ilustración: desarrollar las esferas de la ciencia, la moralidad y el arte de acuerdo con su lógica interna... y su espíritu es una construcción cultural que se basa en condiciones específicas. (Foster, 1988: 8)

al actuar, el hombre de la modernidad se condensa, en algún momento, en

la intención anarquista de hacer estallar la continuidad de la historia, [ello] podemos considerarlo como la fuerza subversiva de esta nueva conciencia histórica. La modernidad se rebela contra las funciones normalizadoras de la tradición... vive de la experiencia de rebelarse contra todo lo que es normativo. (Habermas, 1988: 22). 
El mismo autor, retomando a Max Weber, afirma que la modernidad cultural asiste a la separación de la razón sustantiva expresada por la religión y la metafísica en tres esferas que son la ciencia, la moralidad y el arte, que llegan a diferenciarse porque las visiones del mundo unificadas de la religión y la metafísica se separan... El proyecto de modernidad formulada en el siglo XVIII por los filósofos de la Ilustración consistió en sus esfuerzos para desarrollar una ciencia objetiva, una moralidad y leyes universales y un arte autónomo acorde con su lógica interna (Habermas, 1988: 27-28).

Y aunque sea en el siglo XVIII el tiempo de su enunciación, la "conciencia radicalizada de modernidad", siempre según Habermas, arranca al alborear el siglo XIX y se consolida en su segunda mitad. A partir de entonces, se presentará una tensión, una oposición abstracta, entre lo moderno (lo nuevo) y la tradición; se da aquí el diálogo conflictivo entre presente y pasado, porque la modernidad une desuniendo (Berman, 1988) y lo permanente es precisamente lo efímero, lo eterno es lo fugitivo. Aún somos herederos de tal conciencia histórica, la cual explota con la Revolución Francesa y se condensa en la triada libertad/fraternidad/igualdad, misma que articula el proyecto de la modernidad "inacabada" o "incompleta" hasta hoy, dado que sus guías, conformadoras de la triada mencionada, todavía esperan ser cumplidas.

Un crítico de la anterior postura, Jean-Francois Lyotard, afirma

que el proyecto moderno (de realización de la universalidad) no ha sido abandonado ni olvidado, sino destruido, liquidado.... Auschwitz puede ser tomado como un nombre paradigmático para la no realización trágica de la modernidad. (1987: 30).

Conspicuo miembro del clan teórico de la posmodernidad, Lyotard es, para algunos autores, una especie de postmarxista, que pregona "un informe sobre ele estado actual del espíritu de un sector de la intelectualidad occidental traumatizada por las decepciones sufridas desde 1968." (Picó, 1990: 11). La posmodernidad, según Lyotard, no es un momento de crisis en el constante progreso de la modernidad, sino la ruptura radical con la lógica del camino único (los metarelatos de la ilustración francesa y la transformación totalizadora de la tradición hegeliano/marxista alemana); no es posible su renovación en el ahora, como sí había ocurrido hasta el inicio del siglo XX. Frente a esto Habermas opone una crítica/convocatoria/apuesta/propuesta: cierto que el siglo $\mathrm{XX}$ ha puesto en una ruda prueba el optimismo de la modernidad, pero ésta no es una causa perdida, sino que se requiere un rearmado del proceso racionalizador que teóricamente reconstruya el proyecto, eliminando las patologías que cíclicamente han aparecido en su desarrollo. Y la apuesta/ propuesta queda establecida en Teoría de la acción comunicativa, obra cimera del autor y síntesis del pensamiento sociológico, en la cual se trata de demostrar 
la articulación entre vida cotidiana y sistemas sociales (cómo cada uno presupone al otro); en la sociedad moderna, según Habermas, se da un proceso de selección racional y esta selectividad supone la existencia de alternativas, luego entonces no existe una lógica inevitable de la modernidad y ello, posibilita explicar y diagnosticar sus patologías (1987). Como quiera que sea, Lyotard coincide al entender a la modernidad como un modo: "no es una época sino más bien un modo (en el origen latino de la palabra) en el pensamiento, en la enunciación, en la sensibilidad." (1987: 35). Y este modo, que legitimaba y criticaba sus actos y saberes en nombre de la emancipación, de la sociedad sin clases, de la realización del Espíritu (los metarelatos en pro del "pueblo"), se resquebrajó a fines de los años cincuenta de nuestro siglo, cuando las sociedades entraron en la edad de la postindustrialización y las culturas en la edad posmoderna (Lyotard, 1990).

Vale aquí hacer un paréntesis para esbozar algunas posturas acerca del debate modernidad-posmodernidad. Y si bien Lyotard habla de un nuevo modo que suple al viejo modo moderno y hoy ya aniquilado, hay quienes se definen rotundamente modernos y brindan por la modernidad (Habermas y Berman, por ejemplo) y otros autores enfrentan el debate matizándolo. Entre estos últimos se encuentran Umberto Eco (1985) y Leszek Kolakowski (1990). El primero afirma (en acuerdo con Lyotard) que el posmodernismo es una categoría espiritual... una manera de hacer.... [y que podemos asegurar (disintiendo con Lyotard) que cada época tiene su propio posmodernismo.... Que en todas las épocas se llega a momentos de crisis... que toda respuesta a lo moderno consiste en reconocer que, puesto que el pasado no puede destruirse -su destrucción conduce al silencio-, lo que hay que hacer es volver a visitarlo; con ironía, sin ingenuidad (72-74).

Esto sería, para Eco, el posmodernismo, una reacción que se da adentro mismo del proyecto moderno, sería el mismo caso en que, por ejemplo, Octavio Paz habla de las vanguardias y la persistencia frente a las llamadas postvanguardias (1974) o los modernismos de que habla Berman, o sea las expresiones que se dan en la modernidad y que, en su relación dialéctica con la modernización, le definen el rostro a la propia modernidad (1988): una

experiencia que... se construye a sí misma a través de procesos modernizadorés (científicos, tecnológicos, económicos, políticos...) provocando que los hombres, vueltos sujetos/objetos de ella, manifiesten visiones, ideas, valores y sentires modernistas. (García Niño, 2000: 151).

Kolakowski, por su parte, expresa que la modernidad ha estado siempre a prueba, que el enfrentamiento entre lo viejo y lo nuevo es probablemente eterno y jamás nos lo quitaremos de encima, puesto que expresa la tensión natural entre estructura y evolución, [que toda] crítica de la modernidad... 
podría verse, en su inmensa variedad, como un órgano de autodefensa de nuestra civilización, pero hasta ahora no ha logrado que la modernidad deje de avanzar a velocidad sin precedentes... [no es posible] estar en pro o en contra de la modernidad, a secas, no sólo porque es ocioso tratar de detener el desenvolvimiento de la tecnología, la ciencia y la racionalidad económica, sino porque tanto la modernidad como la antimodernidad pueden expresarse en formas bárbaras y antihumanas. (10,20-23).

Se puede abundar en el debate acudiendo a Bell (1990), Vattimo (1986), Foster (1985), Lipovetsky (1986, 1996), Berman (1988), Paz (1974) y a la excelente antología y comnpendio de posiciones en Picó (1990); asimismo, con relación a la discusión, Touraine (1973), Beck (1998) y Cahoone (2000).

Un autor más cercano, en muchos sentidos, a nosotros, y que aborda de manera provocadora los conceptos de modernidad, cultura y ciudad es Bolivar Echeverría (1998), quien entiende a la modernidad como

el carácter peculiar de la forma histórica de totalización civilizatoria que comienza a prevalecer en la sociedad europea en el siglo XVI, [cuyo] fundamento parece encontrarse en la consolidación indetenible... de un cambio tecnológico que afecta a la raíz misma de las múltiples civilizaciones materiales del ser humano a todo lo ancho del planeta. (144)

En cierta coincidencia con Habermas, a pesar de que en su bibliografía no aparece ningún texto de éste, Echeverría afirma que la modernidad ha tenido varias modernidades (iposmodernidades, en el sentido que lo entiende Eco?), mismas que no han "agotado" a aquella y que sí han despertado nuevas perspectivas de autoafirmación. De todas las modernidades, la más alta en su potencialidad es la sociedad industrial capitalista que se consolida y explota en el siglo antepasado, la cual es contradictoria en sí misma. Así, el racionalismo moderno, el triunfo de las luces del entendimiento sobre la penumbra del mito, que implica la reducción de la especificidad de lo humano al desarrollo de la facultad raciocinante y la reducción de ésta al modo en que ella se realiza en la práctica puramente técnica o instrumentalizadora del mundo, es el modo de manifestación del humanismo propio de la modernidad capitalista (154).

Más adelante (luego de indagar en torno a la relación entre modernidad y cultura) sustentará que el humanismo moderno, y su constitución del mundo de la vida, se encamina no sólo a construir el tiempo social, sino también el espacio social: la ciudad moderna. En tal sentido lo retomaremos en el abordaje por venir, en tanto dejaremos claro que los autores mencionados serán nuestro apoyo y que con ellos dialogaremos cuando hablemos de la modernidad, ya que aportan los puntos centrales que nos interesan para 
nuestro trabajo, los cuales fueron ya enunciados al inicio de este subapartado. Cedamos, ahora, el paso al continente.

\section{El continente}

De entrada, quisiéramos presentar en este subapartado una breve revisión de los postulados fundamentales acerca de la ciudad, del espacio urbano, que aparecen en "los clásicos" (Marx, Durkheim y Weber). Para tal cometido seguiremos la síntesis que José Luis Lezama lleva a efecto de manera notable (1998: 126-130) y que vislumbra en Marx una idea de ciudad como espacio de la distribución de mercancías y territorio del poder, como resultado de la inequitativa distribución de los medios de producción; la ciudad industrial es así el escenario en el cual se echa a andar el modo de producción capitalista, la gran fábrica donde el obrero individualizado se convierte en el obrero colectivo (la clase obrera), en la cual analiza las condiciones de alimentación y vivienda para ejemplificar la injusticia (cosa que también ocurre en el campo, por cierto). Para Weber, la ciudad es el escenario en el cual se da la aparición histórica de una ética racional e individual en los económico, que también tiene que ver con la política y la administración, además: la ciudad genera, dadas sus características de espacio ampliado, relaciones humanas superficiales, pero aquí también surgen el derecho racional y la ciudadanía y posibilita los encuentros de fuerzas que conducen al proceso de racionalización, que impulsará y sustentará la emergencia del Estado burocrático moderno y de la propia ciudad. En Durkheim, la ciudad es el lugar donde se presentan problemas sociales, donde se da lo que él llama solidaridad orgánica (la interdependencia a partir de la división del trabajo y espacio donde se afecta de manera negativa la condición de los hombres, donde las patologías suicidas se presentan con mayor frecuencia a causa de las deficiencias para la cohesión grupal e individual. Hasta aquí los clásicos, según Lezama.

Retomando las líneas centrales de los autores citados, más otros que han enfrentado su estudio (Mumford, 1996; Benjamin, 1982, 1989; Echeverría, 1998, Calvino, 1972) plantearemos nuestra concepción de ciudad (espacio urbano) de manera operativa para los efectos que pretendemos. La ciudad es así el teatro del intercambio y construcción de lo simbólico, la sede de la puesta en escena de la obra vital donde se establece la circulación de productos culturales disímbolos, espacio demarcado en los político y administrativo pero sin fronteras en lo cultural, puesto de mando y conformada por lo elementalmente humano: el diálogo como sustento de la comunicación. La ciudad moderna, que toma al París decimonónico como arquetipo, es el ámbito de lo definitivamente público, es la provocadora del deslinde entre 
vida privada y vida pública (Prost y Vincent, 1987), es el terreno de lo efímero y la velocidad (Berman, 1988), sede de los cafés, los parques, los jardines, las plazas, los pasajes, los cines, los teatros, los cines, los bares, los hoteles... los lugares de encuentro, de comunicación, pues. "la ciudad dice todo lo que debes pensar, te hace repetir su discurso." Calvino, 1972: 23). En ella se da el intercambio de mercancías y objetos (materiales y simbólicos) en ascenso y en descenso (García Canclini, 1990, 1993). En sentido muy amplio, heterodoxo e incluyente en términos teóricos, empíricos e históricos, el espacio de lo citadino

bajo sus distintas expresiones y en sus diversos contextos sociales ha sido, en alguna medida, sinónimo de diversidad, de pluralidad y de valores y conductas que han recorrido caminos similares a aquellos que conducen a la racionalización y que han desembocado en la sociedad moderna. Esta es una sociedad que ha llevado lo urbano a su máxima expresión (Lezama, 1998: 116).

Quede así el continente definido, el cual es posible sufra modificaciones en su conceptualización a la luz de lo que aporten las precisiones del contenido, de la cultura y sus expresiones plurales. A manera de engrane entre ambos conceptos citamos largo:

En el centro, la city, el lugar de la actividad incansable y de la agitación creativa, 'el abismo en el que se precipita el presente' o el sitio donde el futuro brota y comienza a realizarse. Y, desplegada entre los dos, entre la periferia y el núcleo, la constelación de los conglomerados citadinos, unidos entre sí por la nervadura del sistema de comunicación: el espacio urbano, el lugar del tiempo vivo que repite en su traza la espiral centrípeta de la aceleración futurista -y reparte también, sobre el registro topográfico, la jerarquía del dominio. (Echeverría, 1998: 153)

\section{El contenido}

Posiblemente uno de los términos más difíciles de conceptualizar, a causa de las ópticas, corrientes, escuelas y tradiciones existentes sea el de cultura. Jabonoso y poroso en esencia, se ha visto sometido a un tráfago histórico al cual han acudido diversas disciplinas, tanto científicas como artísticas, y en este proceso genético conceptual el manoseo no ha impedido arribar a ciertos acuerdos, a cierto consenso, susceptible de ser compartido por muchos y por muchos también rebatido, en aras de la libertad que busca operativizarlo y hacerlo acorde a las necesidades específicas de quien lo convoca y aplica. Así, han nacido "recortes" como los de cultura de clase (Lenin, 1973; Trotsky, s/f), cultura nacional (Blanco, 1982; Aguilar Camín, 1976; Gilly, 1981; Monsiváis, 
1981), cultura(s) popular(es) o subalterna(s) (Gramsci, 1975; García Canclini, 1982; Cirese, 1979; Monsiváis, 1981; Bajtin, 1974), cultura urbana (Blanco, 1989), cultura... Pero, a fin de cuentas, de los tales recortes se ha edificado el concepto en una intentona donde se deja ir por delante lo incluyente integrador y se elude lo excluyente fragmentador. En este orden trabaja Thompson (1991, 1993), rastreando en las huellas del proceso evolutivo del término sus aciertos conceptuales. Él distingue cuatro concepciones: clásica, descriptiva, simbólica y estructural. En la primera, cultura "es un proceso general de desarrollo intelectual o espiritual." (1991: 46), nace en el siglo XVIII europeo y es sinónimo de civilizado. En la segunda, oriunda del siglo XIX, "engloba los valores, prácticas y creencias de un pueblo... es un todo complejo, un vasto y variado rasgo que define la forma de vida de una sociedad en un periodo histórico. [Se analiza] en tanto sistema cultural." (46.47). En la tercera se consideran las expresiones culturales como "acciones significativas que producen objetos significativos y enunciados que requieren una interpretación." (47). La cuarta, estructural, comprende

las formas simbólicas —es decir, las acciones, objetos y enunciados significativos de varios tipos- en relación con contextos y procesos, socialmente estructurados e históricamente específicos en los que, se producen, transmiten y reciben estas formas simbólicas. (47)

Tiempo después, en 1993, Thompson detalló su clasificación, sin embargo, lo fundamental no varió. La explicación de su propuesta estructural la exp0one de la siguiente manera:

Las formas simbólicas se producen, transmiten y reciben... en contextos [que] se encuentran a su vez, socialmente estructurados y estáncaracterizados por instituciones de varios tipos.... Las formas simbólicas están localizadas en el espacio y el tiempo. Los contextos [involucran] asimetrías sistemáticas en la distribución y acceso a recursos de diferentes tipos. Las formas simbólicas circulan en campos estructurados por estas asimetrías, es decir, por las diferencias resultantes entre grupos como las clases sociales, los grupos étnicos o aquellos grupos de individuos definibles en términos de edad, género, ingreso, etc. La distinción entre alta cultura y cultura popular es uno de los aspectos de esta diferenciación social, aunque en contextos particulares estas diferencias son más ramificadas y complejas.... Los fenómenos culturales no se dan en el vacío (1991: 49).

Agregaríamos a lo anterior que en el terreno de la cultura no existe pureza, que los productos culturales circulan en ascenso y en descenso, que no se definen por su origen sino por su uso, que hay procesos de reapropiación y resemantización, que existen la resistencia cultural y la mitificación, que la comunicación masiva (transmisión de mensajes dotados de sentido) funciona 
como soporte al través del cual se dan las modalidades de la transmisión cultural, que la cultura se produce, sí, pero también se consume. Asimismo, que el consumo es "parte de la racionalidad integrativa y comunicativa de una sociedad." (García Canclini, 1991: 7). Hay una lógica simultánea de integración y distinción [en la cual] se conectan los extremos de una sociedad, [y ello] es aún más notable en la convivencia de las grandes ciudades. A través de cómo nos vestimos, de los lugares en que entramos, de los modos en que usamos la lengua y los lenguajes de la ciudad, construimos y reproducimos la lógica que nos vincula, que nos hace ser una ciudad, una sociedad [moderna, agregaríamos] (7).

Atendiendo a lo expresado por García Canclini, nos percatamos de que se está refiriendo a la instancia citadina como espacio de producción y reproducción cultural; en específico a lo que se ha dado en llamar cultura urbana, esa que José Joaquín Blanco define como la correspondiente a "la identidad industrial internacional" (1989: 13), la cual define a la ciudad y la vida propias de la modernidad. La cultura aparece así como la expresión colectiva compartida y en constante conflicto, del cual se toman prestados elementos provenientes de los diversos sectores y agentes sociales. En este proceso de articulación/rearticulación los transeúntes (viajeros urbanos) asisten a una diversidad de espacios públicos en los cuales se da el intercambio y la circulación culturales, son copartícipes (coproductores y consumidores comunitarios) en la generación de significados. Los habitantes de lo urbano somos entes pluriactuantes y multifacéticos: en algunas instancias de lo público privilegiamos la producción cultural, en otros, el consumo, viajamos con nuestra cultura a cuestas, somos portadores y transmisores de signicidad, dialogamos con el entorno y los prójimos y, a partir de esta relación, cobramos y le damos sentido al mundo. Esta es la cultura moderna del siglo que acaba de terminar con el milenio, la misma que inventó al ciudadano, al ser social, luego entonces somos nosotros también creaciones culturales. Tenemos un origen biológico, somos seres vivos en el actuar primario, pero en las estrategias que hemos desarrollado para enfrentar y dar cuenta del entorno, de aprehenderlo, de controlarlo, de nombrarlo y definirlo, se manifiesta nuestra esencia como seres culturales que actúan para sí insertos en rituales comunitarios masivos.. Pertenecemos a comunidades reales y virtuales con sus especificidades culturales, sus dispositivos, sus arsenales. Ejercemos la vida en los mapas que nosotros mismos hemos creado y que, en muchas ocasiones, escapan a nuestro entender y dominio. Cuestión paradójica ésta, resultante de un hecho ineludible: el ser causa y efecto de la cultura, productores y productos de la misma, la que nos da razón de ser (identidad) y de interrogación constante.

La cultura resulta el contenido de la ciudad específica (resultado y dato central) de la modernidad, de nuestra modernidad más cercana, más inmedia- 
ta: la que arranca en la segunda mitad del siglo pasado y atraviesa (quizás maltrecha, pero tozuda) el presente. Modo, continente y contenido quedan hasta ahora cobijados en el albergue conceptual con un detalle adicional: la ciudad y la cultura interactúan de siempre (la primera es el campo de expresión de la segunda) y ambas son definidas por el modo propio de la modernidad, pero la ciudad propicia el amplio espacio de lo público creado precisamente por la tal modernidad. Así, es en la ciudad moderna donde se asienta, produce y reproduce la cultura moderna (abigarrada y barroca de suyo), porque la modernidad propició de manera rotunda (aprehensible teórica y empíricamente) lo que hemos convenido en llamar esfera pública (Habermas, 1998), concepto que amalgamará y acrisolará (que servirá de bisagra) a los tres ya tratados hasta aquí y el cual pasaremos a revisar brevemente para terminara estas líneas.

\section{El terreno de juego}

Siguiendo con el principio de establecer un diálogo conceptual permanente, no exento de conflictos y contradicciones, que permita el confrontar los aciertos y errores propios de toda pesquisa teórica y, además, intentando avanzar en la pavimentación del escenario sobre el cual actuaremos y en el cual asentaremos los pies, es pertinente aclarar por qué elegir el concepto de esfera pública en una doble dimensión, de manera binaria. En un primer sentido lo entenderemos como el(los) espacio(s) originados en el ámbito de los social, en donde los sujetos acuden y se relacionan voluntariamente (por consenso) para dirimir sus puntos de vista y opiniones, procesar información $\mathrm{y}$ acordar en torno a los hechos y actos que les son comunes. En otro sentido, apelaremos a él como el articulador (a manera de bisagra) entre la modernidad, el espacio urbano y la cultura; en tal comprensión esperamos le otorgue su peso real y ponderación a cada uno de éstos. Y de acuerdo a la complejidad que presente la sociedad a enfrentar variará su ubicación: a mayor complejidad social la esfera pública es elemento intermediario entre el sistema político y el espacio privado del mundo de la vida, se convierte en una especie de red de redes que integra geografías cercanas y lejanas.

\section{Postexto}

Con el arsenal teórico y conceptual enunciado interrogaremos a nuestro objeto de estudio, en un constante platicar del cual podemos obtener certezas 
y dudas que busquen nuevas certezas. Porque el acto comunicativo entre la teoría social y la historiografía deviene reclamo finisecular y punto de partida hermeneútico. La tensión pasado-presente $o$, más claro aún, inquirir al pasado desde el presente, es substancia dialógica que de siempre enriquece el saber. Por tal motivo, y con lo hasta ahora expuesto y sabido, haremos un flash back al tema, tiempo y lugar que han originado lo aquí planteado.

\section{Bibliografía}

Aguilar Camín, H. et. al. (1976). En torno a la cultura nacional. México: SEP/ INAH.

Aguilar Mora, J. (1990). Una muerte sencilla, justa, eterna. México: Era.

Bajtin, M. (1974). La cultura popular en le Edad Media y el Renacimiento. Barcelona: Barral.

Barthes, R. (1981). Mitologías. México: Siglo XXI.

Beck, U. (1998). Qué es la globalización. Barcelona: Paidós.

Bell, D. (1990). Las contradicciones culturales del capitalismo. Barcelona: Alianza.

Benjamin, W. (1982). Iluminaciones I: imaginación y sociedad. Madrid: Taurus.

(1982a). Iluminaciones II: poesía y capitalismo. Madrid: Taurus.

(1989). Discursos interrumpidos I. Madrid. Taurus.

Berman, M. (1988). Todo lo sólido se desvanece en el aire. México: Siglo XXI.

Blanco, J. J. (1982). Cultura nacional y cultura de Estado. Cuadernos Políti$\cos ,(34), 75-84$.

-(1989). Cuando todas las chamacas se pusieron medias nylon. México: Joan Boldó i Climent/Enjambre.

Borges, J. L. (1989). Historia universal de la infamia. Buenos Aires: Emecé. (1990). El libro de arena. México: Alianza/Emecé.

Cahoone, L. (2000). Del modernismo al posmodernismo. La palabra y el hombre, (115), 121-143.

Calvino, I. (1972). Las ciudades invisibles. Barcelona: Minotauro.

Cirese, A. M. (1979). Ensayos sobre las culturas subalternas. México: CISINAH.

Del Palacio Montiel, C. (1997). Esfera pública y prensa. Inicios del periodismo en Guadalajara (1809-1835). Comunicación y Sociedad, (31).

De Certeau, M. (1996). La invención de lo cotidiano. México: UIA/ ITESO/CFEMC. 
Eco, U. (1985). Apostillas a El nombre de la rosa. Barcelona. Lumen. Echeverría, B. (1998). La modernidad de lo barroco. México: Era.\}

Foster, H. (Comp.) (1985). La posmodernidad. México. Kairós.

Gadamer, H.-J. (1992). Verdad y método II. Salamanca: Sígueme.

García Canclini, N. (1982). Las culturas populares en el capitalismo. México:

Nueva Imagen.

-(1990). Culturas híbridas... México: Grijalbo.

- (1991). El consumo sirve para pensar. Dia-logos de la Comunicación, (30), 6-9.

-(1993). El consumo cultural en México. México: CNCA.

(1995). Consumidores y ciudadanos. México: Grijalbo.

García Niño, A. E. (1992). Glosas profanas para una crónica que se construye a sí misma en el tiempo. Eslabones, 4, 147-154.

(2000). La persistencia histórica de lo volátil. La Palabra y El Hombre, (115), 151-158.

Gilly, A. (1981). La acre resistencia a la opresión. Cuadernos Políticos, (30), 45-52.

Gramsci, A. (1975). Los intelectuales y la organización de la cultura. México: Juan Pablos.

Habermas, J. (1987). Teoría de la acción comunicativa I. Racionalidad social y racionalidad de la acción. Madrid: Taurus.

- (1987). Teoría de la acción comunicativa II. Crítica de la razón funcionalista. Madrid: Taurus.

(1988). La modernidad, un proyecto incompleto. En Foster, H. (Comp.) La posmodernidad. México: Kairós.

-(1998). Facticidad y Validez. Madrid: Trotta.

Kerik, C. (Comp.). (1993. En torno a Walter Benjamin. México: UAM.

Kofler, L. (1971). Contribución a la historia de la sociedad burguesa. Buenos Aires: Amorrortu.

Kolakowski, L. (1990). La modernidad siempre a prueba. México: Puebla.

Lafaye, J. (1977). Quetzlcóatl y Guadalupe. La formación de la conciencia nacional en México. México: FCE.

Lezama, J. L. (1998). Teoría social, espacio y ciudad. México: Colmex.

Lenin, V. I. (1973). Tareas de las juventudes comunistas. En Obras Escogidas III. Moscú: Progreso.

Lipovetsky, G. (1986). La era del vacio. Barcelona: Anagrama. (1996). El imperio de lo efimero. Barcelona: Anagrama. 
Lyotard, J.-F. (1987). La postmodernidad (enseñada a los niños). Barcelona: Gedisa.

-(1990). La condición postmoderna. México: REI.

Martín-Barbero, J. (1987) De los medios a las mediaciones. México: Gustavo Gili.

Nettel, P. y Arroyo, S. (Eds.). (1997). Aproximaciones a la modernidad. México: UAM-X.

Monsiváis, C. (1981). Notas sobre el Estado, la cultura nacional y las culturas populares en México. Cuadernos Políticos, (30), 33-43.

Mumford, L. (1966). La ciudad en la historia. Buenos Aires: Infinito.

Paz, O. (1974). Los hijos del limo. Barcelona: Seix Barral.

Picó, J. (Comp.). (1990). Modernidad y postmodernidad. Barcelona: Alianza. Prost, A. y Vincent, G. (1987) La vida privada en el siglo XX. En Historia de la vida privada 9. Madrid: Taurus.

Thompson, J. B. (1991). La comunicación masiva y la cultura moderna. Versión, (1), 43-74.

-(1993). Ideología y cultura moderna. México: UAM.

Touraine, A. (1973). La sociedad postindustrial. Barcelona: Ariel.

Trotsky, L. (s/f) Literatura y revolución. Barcelona: Ruedo Ibérico.

Ricoeur, P. (1996). Sí mismo como otro. México: Siglo XXI.

Vattimo, G. (1986). El fin de la modernidad. Barcelona: Gedisa.

Weber, M. (1994). La ética protestante y el espiritu del capitalismo, México: CINAR. 